\title{
A study on mefloquine-associated neuropsychiatric manifestations among Nepalese soldiers posted for United Nations peace mission
}

\author{
Katuwal N', Khatri $\mathrm{D}^{2}$, Shrestha $\mathrm{DB}^{3}$, Dhungel $\mathrm{O}^{4}$, Oli $\mathrm{PR}^{5}$, Aryal BB ${ }^{5}$, Rawal N', Rana KJB${ }^{2}$, Manandhar \\ $\mathrm{P}^{1}$, Panta $\mathrm{C}^{2}$
}

${ }^{1}$ Nagendra Katuwal, Lecturer; Namrata Rawal, Associate Professor; Pradeep Manandhar, Lecturer; Department of Neuropsychiatry, Shree Birendra Hospital, Chhauni; Nepalese Army Institute of Health Sciences (NAIHS). ${ }^{2}$ Devendra Khatri, Associate Professor; Kishor JB Rana, Professor; Chiranjibi Panta, Lecturer; Department of Medicine, Shree Birendra Hospital, Chhauni; NAIHS. ${ }^{3}$ Dhan Bahadur Shrestha, Medical Officer; Mangalbare Hospital, Urlabari, Morang, Nepal. ${ }^{4}$ Omkar Dhungel, Medical Officer; Shree Birendra Hospital, Chhauni. ${ }^{5}$ Prakash Raj Oli \& Barun Babu Aryal, Intern; Shree Birendra Hospital, Chhauni.

\begin{abstract}
Background: Mefloquine is one of the prophylactic medications recommended by the government of Nepal. In areas of intense malaria transmission, prophylaxis with drugs is an important strategy to prevent malaria. During prophylactic use, several neuro-psychiatric and other systemic adverse effects can occur with mefloquine. Notable psychiatric manifestations include anxiety, depression, restlessness, and confusion.

Objective: To study the psychiatric effects of mefloquine in Nepalese serving soldiers posted in the United Nations peace mission nations of the African continent taking mefloquine prophylaxis.

Methodology: This prospective descriptive study was conducted among Nepalese soldiers posted for United Nations peace mission in South Sudan over a period of one year. Soldiers of age group 25-55 years posted for peace mission having no past and family history of psychiatric illnesses were enrolled in the study. General Health Questionnaire-12, translated into Nepali by Nepalese Journal of Psychiatry, with a questionnaire about the side effects was used to collect detailed information.

Results: A total of 524 soldiers posted on peace mission were enrolled in the present study, among which 520 were male and four were female. There were four positive cases with General Health Questionnaire score 3/12 or more. Among the adverse events noted, neuropsychiatric adverse events were more common than non-neuropsychiatric adverse events but none were of life-threatening severity.

Conclusion: In a malaria endemic region with a high prevalence of malaria, mefloquine can be safely used in an apparently healthy population, judging the risk-benefit.
\end{abstract}

Key words: Mefloquine; Nepal army; Neuro-psychiatric manifestation

\section{INTRODUCTION}

$\mathrm{T}$ The number of soldiers going on United Nations (UN) peacekeeping missions annually is around 10,000 with current deployment 4366, in the different countries allocated by the UN' ${ }^{1}$. Malaria is endemic in 109 countries and these countries are visited by more than 125 million

Address for correspondence

Dhan Bahadur Shrestha

Mangalbare Hospital, Urlabari, Morang, Nepal

E-mail:medhan75@gmail.com travelers each year. About 10,000 international travelers from non-endemic areas who lack immunity to malaria fall ill with malaria after returning home from travel to malaria-endemic countries ${ }^{2}$ and the real figure may be up to 30,000 as they were underdiagnosed, treated aboard or underreporting. About $1-4 \%$ of travelers who acquire $P$. falciparum malaria will die. Travelers to subSaharan Africa are most at risk of contracting malaria. Recent estimates suggest an attack rate of malaria of 302 in 100,000 travelers to West Africa compared to lower rates in Southern Africa $(49 / 100,000)$ and much 
lower rates in East Asia $(5.4 / 100,000)$ and the Americas $(1 / 100,000)^{3}$. In Nepal, there were 1,674 confirmed cases of malaria in 2070/71 B.S, with 585 imported cases. The proportion of $P$. falciparum infections were 13 percent in the reporting year. The total $P$. falciparum cases were 224 and among them, 142 were imported ${ }^{4}$. Most cases of imported malaria are preventable using appropriate chemoprophylaxis, but many travelers fail to use or comply with appropriate chemoprophylaxis ${ }^{5}$. An important factor contributing to this failure is the concern about side effects associated with antimalarial chemoprophylaxis. Along with atovaquone/proguanil and doxycycline, mefloquine is currently recommended as malaria prophylaxis for travel in areas with chloroquine-resistant Plasmodium falciparum ${ }^{6}$.

There have been many neuropsychiatric disturbances of mefloquine use reported in the literature since its use in therapy for malaria treatment and prophylaxis. In spite of this, it is in use in several countries as a prophylactic agent these days too $^{3}$. During prophylactic use, the occurrence of psychiatric symptoms such as acute anxiety, depression, restlessness or confusion suggests a risk for more serious psychiatric disturbances or neurologic adverse reactions ${ }^{6}$. Though there are many reports from the all over the world, the neuropsychiatric manifestations among Nepalese soldiers using mefloquine as a prophylactic medication for malaria are unknown.

In order to investigate these effects, this prospective study was conducted on Nepalese serving soldiers posted in UN peace mission nations of the African continent taking mefloquine prophylaxis to observe the psychiatric effects of mefloquine.

\section{METHODOLOGY}

The study was conducted among Nepalese soldiers deployed for UN peace mission in South Sudan. This was a descriptive study conducted over a period of one year from $15^{\text {th }}$ Aug 2015 to $15^{\text {th }}$ Sept 2016.

Inclusion criteria: Nepalese soldiers of age group 2555 years posted for UN peace mission, confirmed to be taking mefloquine, and having no past and family history of psychiatric illnesses.

Exclusion criteria: Soldiers having a past history of neuropsychiatric disorders or a family history of neuropsychiatric disorders, seizure disorder, head injury, excessive alcohol consumption and those below the age of 25 and above the age of 55 years.
General Health Questionnaire-12 (GHQ-12), a validated scale developed to measure mental health? ${ }^{7}$. Its translated version from English to Nepali by Nepalese Journal of Psychiatry was used in the study to identify a deviation in mental health among serving soldiers under mefloquine prophylaxis. In addition to $\mathrm{GHQ}$, mefloquine side effect questionnaire (developed by Lariam action; an independent information and support group for people with mefloquine toxicity) was used in an interview to collect detailed information about health condition before, during and after the completion of mefloquine prophylactic regimen. These questionnaires were used by medical officer posted on UN mission (coauthor of this study) to collect the data. The GHQ was considered positive if it came with score $\geq 3 / 12$. Among positive cases, further detailed inquiry was made to dig down the problem patient was having, using a side effect questionnaire to get the systemic symptomatology.

During that time period, the subjects were informed about the nature of the study and informed consent was obtained. They were asked about their previous illness, any family history of psychiatric illness, history of seizure or alcohol abuse. Then, they were provided with a questionnaire and asked to tick on the true options regarding their health state. About 50 subjects were dealt on a daily basis and completed in around 10 days. The reassessment was repeated every 4 months with a total of four assessments done by the same medical officer. Two assessments were done in Nepal at Shree Birendra Hospital (before commencing treatment and after completion of the regimen); rest two assessments were done in Sudan.

Any participant having three or more criteria positive in GHQ was identified as positive. The positive cases were followed up closely, keeping their identity a secret by supervising medical officer in Sudan. Among positive cases, mefloquine was stopped and provided with protective measures for a mosquito bite. The follow up (twice a week) and counseling about the side effects of mefloquine helped most of the positive cases, while in one of them tablet diazepam $5 \mathrm{mg}$ was given for sleeplessness and anxiety for 5 days. All cases were followed up four-monthly and their physical and psychological conditions were closely observed. All patients were provided with medication under direct supervision. Being army personnel was the one who gets exposed to long term prophylactic mefloquine therapy and most previous study were a case based this study was carried out. 
The institutional ethical review committee of NAlHS granted the ethical clearance to conduct this study. The Nepal army corps, Director General of Medical Services (DGMS) gave the permission to conduct the study. Explained written consent was taken from all the participants voluntarily.

\section{RESULTS}

Out of the total 524 soldiers enrolled, 520 were male and rests 4 were females. There were 4 positive cases with a $\mathrm{GHQ}$ score $\geq 3 / 12$. Each positive case reported multiple adverse events. The incidence rate of mefloquineassociated neuropsychiatric manifestations is 7.6 cases per 1,000 study populations. Mean age was $32.26 \pm 4.62$ years with age ranging from 23-53 years.

\section{Table 1: Mefloquine-associated adverse} manifestations

\begin{tabular}{lcc}
\hline Adverse events & Number (s) & $\%$ \\
\hline Neuropsychiatric adverse events & & \\
\hline Insomnia/sleep disturbances & 3 & 0.57 \\
\hline Headache & 3 & 0.57 \\
\hline Memory impairment, confusion & 2 & 0.38 \\
\hline Dizziness or vertigo & 2 & 0.38 \\
\hline Blurred or double vision & 2 & 0.38 \\
\hline Difficulty in concentration & 1 & 0.19 \\
\hline Abnormal dreams & 1 & 0.19 \\
\hline Aggression & 1 & 0.19 \\
\hline Psychotic episodes & 1 & 0.19 \\
\hline Mood swings/changes & 1 & 0.19 \\
\hline Loss of coordination & 1 & 0.19 \\
\hline Suicidal ideation & 1 & 0.19 \\
\hline Non-neuropsychiatric adverse events & & \\
\hline Disturbances in heartbeat & 2 & 0.38 \\
\hline Fatigue, malaise & 1 & 0.19 \\
\hline Neck pain & 1 & 0.19 \\
\hline Abdominal pain, diarrhea & 1 & 0.19 \\
\hline Muscle and joint pain & 1 & 0.19 \\
\hline
\end{tabular}

Among the different adverse events reported, neuropsychiatric adverse events were quite more frequent than non-neuropsychiatric adverse events. None of the reported adverse events were of lifethreatening severity. Among different reported neuropsychiatric adverse events, insomnia/sleep disturbances and headache were more common $(n=3)$ followed by memory impairment, confusion, dizziness or vertigo and blurred or double vision $(n=2)$ while among non-neuropsychiatric adverse events, disturbance in heartbeat was common (and=2) (Table 1.).

\section{DISCUSSION}

In the United Nations (UN) peace mission, Nepalese soldiers gets deployed in the countries allocated by the UN'. Mefloquine is one of the prophylactic medications recommended by the government of Nepal for soldiers going into different malarious countries in Africa ${ }^{8}$.

Mefloquine has a long elimination half-life of 14 to 41 days, which allows for once-a-week dosing and makes it a popular choice as malaria prophylaxis for travelers to malaria-endemic areas ${ }^{5}$. The current recommended prophylactic dose is $250 \mathrm{mg}$ once a week for adults 9 . Since mefloquine was introduced in 1985, the most commonly reported adverse events were gastrointestinal and neuropsychiatric events $s^{7,10}$. Psychiatric symptoms after taking mefloquine range from restlessness, aggression, unease, a sense of impending doom, phobias, magical thinking ${ }^{12}$, agitation ${ }^{10,11}$ memory impairment ${ }^{11,12}$, auditory or true visual hallucinations ${ }^{15,16,20,21}$ frequently involving religious or morbid themes ${ }^{11}$, insomnia ${ }^{10,16,21,22}$, abnormal dreams $s^{11,12,15}$, anxiety ${ }^{12,13,15}$, paranoia ${ }^{13,14}$, panic $\operatorname{attacks}^{14,15,19}$, personality change ${ }^{12,13,15}$, dizziness ${ }^{17,19,21,24,25}$, psychotic behaviour ${ }^{19,21-24,27}$, suicidal ideation ${ }^{19,22-24,27}$ and suicide ${ }^{13,14,22,23}$, delusions ${ }^{17,19,23,25-27}$, persecutory mania ${ }^{16,19,24-27}$, depression ${ }^{22-27}$ to hallucinations ${ }^{15,22,24-27}$ and sleep disturbances ${ }^{19,21,24-26}$. Such symptoms have been reported after only a single 250-mg tablet and may progress in severity with subsequent doses. In some cases, these symptoms have been reported to continue for months or years after mefloquine has been stopped ${ }^{16}$.

Neurologic symptoms such as tinnitus ${ }^{10}$, dizziness ${ }^{10,12,24}$ or vertigo ${ }^{10,14,22}$, convulsions ${ }^{14,19,21,24,25}$ and loss of balance ${ }^{13,15,19,20}$ may develop. During prophylactic use, if above mentioned neurologic symptoms occur, the drug should be discontinued, and an alternative medication should be substituted..$^{15}$ In the present study, in all four cases, mefloquine was held and only preventive ways like the use of mosquito repellant and net were used. Mefloquine is highly effective in preventing malaria, but articles in the medical and lay press that highlight the neuropsychiatric side effects of mefloquine have caused many travelers to use less-effective alternatives or to avoid chemoprophylaxis altogether ${ }^{6}$. This large study on Nepalese troops deployed in UN peace mission found mefloquine to be relatively safe in an apparently healthy population with only four $(7.6 / 1,000)$ positive cases with $\mathrm{GHQ} \geq 3$. Among neuropsychiatric adverse events associated with mefloquine, insomnia/ sleep disturbances and headache were more common (and=3) followed by memory impairment, confusion, dizziness or vertigo and blurred or double vision $(n=2)$ 
in the present study. Additionally, most of the previous adverse events related reports on mefloquine were case based studies ${ }^{18-21,23}$. So, with proper screening of the individual to rule out any systemic illnesses, mefloquine can be used safely as a prophylactic agent while moving to malarious prone zone judging the benefit over the risk.

This study was based on Nepalese troops posted in Sudan for UN peace mission taking mefloquine as prophylactic regimen so its major limitation could be its generalizability to all populations and ethnicity. So, randomized study including different population is the next step ahead to explore the safety of mefloquine.

\section{CONCLUSION}

Mefloquine can be safely used in apparently healthy individuals where malaria is endemic with a high prevalence rate, judging the benefit over the risk of not using it. Individuals should not avoid chemoprophylaxis with mefloquine based on unnecessarily sensationalized media coverage. Though this non-randomized study; based on Nepalese adult population (soldiers) its generalizability may not be applicable in all population groups so further well-designed study including other ethnic population is next to explore the safety of mefloquine.

\section{ACKNOWLEDGMENT}

We would like to acknowledge the deployed troops without whom study would not have been possible. Also, we would like to acknowledge the Nepalese army corps for granting permission and needful help to conduct this study.

Department of Health Services, Ministry of Health and Population; 2011 Dec. 86p.[FullText]

9. White NJ, Breman JG. Malaria. In: Kasper D, Fauci A, Hauser S, Longo D, Jameson J, Loscalzo J, editors. Harrison's Principles of Internal Medicine $19^{\text {th }} \mathrm{ed}$. New Delhi: McGraw-Hill Education; 2015. p.1368-87.

10. Overbosch D, Schilthuis $H$, Bienzle $U$, Behrens RH, Kain KC, Clarke PD et al. Atovaquone-proguanil versus mefloquine for malaria prophylaxis in nonimmune travelers: results from a randomized, double-blind study. Clinical Infectious Diseases. 2001 Oct 1;33(7):1015-21.[DOI]

11. Tuan TM, Browning J, Dell ML. Psychosis with paranoid delusions after a therapeutic dose of mefloquine: a case report. Malaria Journal. 2006 Dec;5(1):74.[DOI]

12. Ritchie EC, Block J, Nevin RL. Psychiatric side effects of mefloquine: applications to forensic psychiatry. Journal of the American Academy of Psychiatry and the Law Online. 2013 Jun 1;41(2):224-35. [PubMed]

13. Teva Pharmaceuticals. Mefloquine Hydrochloride Tablets USP [Internet]. Sellerville, PA, USA: Teva Pharmaceuticals; 2013[Assessed on March 20, 2018] [Full Text]

14. Schlagenhauf P. Mefloquine for Malaria Chemoprophylaxis 1992-1 998: A Review. J Travel Med1999; 6: p. 122-33. [FullText]

15. Schlagenhauf $P$, Steffen R. Neuropsychiatric events and travel: do antimalarials play a role? Journal of travel medicine. 2000 Sep 1;7(5):225-7. [PubMed]

16. Barrett PJ, Emmins PD, Clarke PD, Bradley DJ. Comparison of adverse events associated with use of mefloquine and combination of chloroquine 
and proguanil as antimalarial prophylaxis: postal and telephone survey of travelers. BMJ. 1996 Aug 31;313(7056):525-8.[PubMed]

17. Organisation Mondiale de la Sante WHO. Review of central nervous system adverse events related to the antimalarial drug, mefloquine (1985-1990) (WHO/MAL 911063). Geneva: WHO;1991.31 p. [FullText]

18. Oueriagli FN, Touhami M, Laffinti A, Abilkacem L. Mood disorder after malaria prophylaxis with mefloquine (two case reports). L'Encephale. 2011 Oct;37(5):393-6. [DOI]

19. Borruat FX, Nater B, Robyn L, Genton B. Prolonged visual illusions induced by mefloquine (Lariam ${ }^{\circledR}$ ): a case report. Journal of travel medicine. 2001 May 1;8(3):148-9. [PMID]

20. Thapa R, Biswas B. Childhood mefloquine-induced mania and psychosis: a case report. Journal of child neurology. 2009 Aug;24(8):1008-9.

21. Folkerts $H$, Kuhs $H$. Psychotic episode caused by prevention of malaria with mefloquine. A case report. Der Nervenarzt. 1992 May;63(5):300-2. [FullText]
22. Meszaros K, Kasper S. Psychopathological phenomena in long-term follow-up of acute psychosis after preventive mefloquine (Lariam) administration. Der Nervenarzt. 1996 May;67(5):4046.

23. Tor PC, Lee HY, Tan CH. Mefloquine-induced mania in a 22-year-old Chinese man. Singapore medical journal. 2006 Jun;47(6):549-50.[PubMed]

24. Fuller SJ, Naraqi S, Gilessi G. Paranoid psychosis related to mefloquine antimalarial prophylaxis. PAPUA NEW GUINEA MEDICAL JOURNAL. 2002 Sep;45(3/4):219-21. [PubMed]

25. Office of the Assistant Secretary of defense. Policy Memorandum on the Use of Mefloquine in Malaria Prophylaxis. [Internet]. Washington: Office of the assistant secretary of defense. [Website]

26. Even C, Friedman S, Lanouar K. Bipolar disorder after mefloquine treatment. Journal of Psychiatry and Neuroscience. 2001 May; 26(3):252. [PubMed]

27. Rønn AM, Rønne Rasmussen J, Gøtzsche PC, Bygbjerg IC. Neuropsychiatric manifestations after mefloquine therapy for Plasmodium falciparum malaria: comparing a retrospective and a prospective study. Tropical Medicine \& International Health. 1998 Feb 1;3(2):83-8. [DOI] 